\title{
Perencanaan Pelaksanaan Abdimas Edukasi Pemanfaatan Teknologi Bagi Usaha Mikro Kecil Menengah (UMKM) Kelurahan Tanjung Duren Jakarta Barat
}

Iwan Aang Soenandi ${ }^{1}$, Bambang Siswanto ${ }^{2}$, Dwi Aprillita ${ }^{3}$, Roseline Manuela Anwar ${ }^{4}$, Lambok Tampubolon ${ }^{5}$, Diana Frederica $^{6}$, Febriani Cristina Susianti Magdalena ${ }^{7}$, Meriastuti Ginting ${ }^{8}$, Florensa Rosani Purba ${ }^{9}$

\author{
${ }^{1,8}$ Program Studi Teknik Industri,Universitas Kristen Krida Wacana \\ Jl. Tanjung Duren Raya No. 4 Jakarta Barat 11470 \\ 1iwan.as@ukrida.ac.id \\ ${ }^{8}$ meriastuti.ginting@ukrida.ac.id \\ ${ }^{2,3,4}$ Program Studi Manajemen,Universitas Kristen Krida Wacana \\ Jl. Tanjung Duren Raya No. 4 Jakarta Barat 11470 \\ bambang.siswanto@ukrida.ac.id \\ ${ }^{3}$ lita@ukrida.ac.id \\ ${ }^{4}$ roseline.anwar@ukrida.ac.id \\ ${ }^{5,6,7}$ Program Studi Akuntansi,Universitas Kristen Krida WacanaJakarta \\ Jl. Tanjung Duren Raya No. 4 Jakarta Barat 11470 \\ ${ }^{5}$ lambok.tampubolon@ukrida.ac.id \\ 6diana.frederica@yahoo.com \\ ${ }^{7}$ febriani.magdalena@ukrida.ac.id \\ ${ }^{1,8}$ Program Studi Teknik Informatika,Universitas Kristen Krida Wacana \\ Jl. Tanjung Duren Raya No. 4 Jakarta Barat 11470 \\ ${ }^{9}$ florensa.purba@ukrida.ac.id
}

\begin{abstract}
Abstrak - Pemerintah berupaya untuk membantu masyarakat dalam meningkatkan perekonomian khususnya di bidang Usaha Mikro Kecil Menengah (UMKM). Berdasarkan Undang- Undang No 20 Tahun 2008 (UU 20/2008) dikemukakan bahwa UMKM adalah sebuah perusahaan kecil yang dimiliki dan dikelola oleh seseorang atau dimiliki oleh sekelompok kecil orang dengan jumlah dan kekayaan dan pendapatan tertentu. Peran UMKM sangat penting dalam perekonomian negara, karena sektor UMKM merupakan penyumbang Produk Domestik Bruto (PDB) terbesar. Untuk mendukung hal tersebut Pemerintah berupaya semaksimal mungkin mencari berbagai macam cara agar UMKM dapat terus berjalan dengan baik dan stabil. Pemerintah menggandeng Perguruan Tinggi untuk turut serta berupaya membantu UMKM agar terus berkembang. Sebagai implementasi program Pengabdian kepada Masyarakat, Fakultas Ekonomi dan Bisnis (FEB) dan Fakultas Teknik dan Ilmu Komputer (FTIK) UKRIDA berupaya merancang satu kegiatan yang bermanfaat bagi UMKM yakni melalui edukasi
\end{abstract}

berupa pendampingan pengurusan izin usaha dan penyuluhan mengenai pemanfaatan teknologi agar penjualan produk mereka menjadi lebih optimal. Selain dapat membantu mereka untuk menaikkan taraf hidup perekonomian keluarga, FEB dan FTIK UKRIDA juga telah berkontribusi mendukung salah satu program Pemerintah dalam meningkatkan kesejahteraan masyarakatnya. Hal ini juga sebagai wujud nyata dalam mengimplementasikan salah satu kegiatan Tridharma Perguruan Tinggi yaitu dalam bidang pengabdian kepada masyarakat.

Kata kunci-UMKM, edukasi, teknologi, penjualan, optimal.

Abstract-The government make effort to assist the society in improving the economy, especially in the field of micro and small enterprises (SMEs). According to Law Number (No). 20 of 2008 states that SME are small companies owned and managed by a person or owned by a small group of people with 
a certain amount of wealth and income. The role of SMEs is very important in the country's economy, because the SMEs sector is the largest contributor to Gross Domestic Product (GDP). To support SMEs, the Government is trying to find various ways so SMEs can continue to run well and stable. The government cooperates with Universities to help SMEs continue to advance and develop. As one of the universities, the Faculty of Economics and Business (FEB) UKRIDA and Faculty of Engineering and Computer Science (FTIK) seek to design an activity that is beneficial to SMEs through providing education in the form of socialization or counselling about introduction and how to manage business permit and use technology to optimize their product sales. Besides being able to help them improve their family's economic standard of living, FEB and FTIK UKRIDA have also contributed to support one of the Government's programs in improving the welfare of its people. This is also form of implementing community service as one of the tridharma activities in Higher Education.

Keywords—SMEs,education, technology, sales, optimal.

\section{Pendahuluan}

Keputusan Menteri Koperasi dan Pembinaan Pengusaha Kecil Nomor 961/KEP/M/XI/1995 berbunyi: kewirausahaan adalah semangat, sikap, perilaku dan kemampuan seseorang dalam menangani usaha atau kegiatan yang mengarah pada upaya mencari, menciptakan, serta menerapkan cara kerja, teknologi dan produk baru dengan meningkatkan efisiensi dalam rangka memberikan pelayanan yang lebih abik dan atau memperoleh keuntungan yang lebih besar. Kewirausahaan merupakan hal atau usaha yang berkaitan dengan penciptaaan suatu kegiatan atau usaha atau aktivitas atas kemauan sendiri dan mendirikan usaha atau suatu bisnis dengan kemauan dan kemampuan sendiri [1] Usaha yang memiliki dampak yang luar biasa dan menjadi penyumbang perekonomian terbesar di Indonesia adalah adanya keberadaan Usaha Mikro Kecil Menengah (UMKM). Peran UMKM sangat strategis dalam mengurangi tingkat kemiskinan, karena UMKM mampu menciptakan peluang kerja baru sehingga mengurangi tingkat pengangguran [2]

Walaupun UMKM dianggap sebagai penyumbang terbesar dalam bidang perekonomian negara di Indonesia, ternyata UMKM juga memiliki banyak tantangan dalam mempertahankan kestabilan pendapatannya. UMKM dituntut untuk dapat bersaing di tengah keadaan Pandemi yang terjadi lebih dari setahun hingga saat ini. UMKM harus mampu bekerja lebih keras untuk dapat bersaing baik dalam mengasah Sumber Daya Manusia (SDM), dan juga dalam mendapatkan calon pelanggannya. Untuk dapat mendukung perkembangan UMKM tersebut perlu ada pemanfaatan teknologi agar tidak tertinggal. Apabila UMKM dapat menggunakan pemanfaatan teknologi secara optimal, sedikitnya akan membantu UMKM dalam menghadapi persaingan bisnis online yang ketat [3]

Masuknya era digitalisasi dalam bisnis mengharuskan UMKM mengikuti penyesuaian-penyesuaian untuk memudahkan jalannya operasional bisnis dalam menerapkan metode bisnis berbasis teknologi dan berbasis online agar pemasaran cepat berkembang [4] dan dapat terhindar dari kebutuhan modal yang besar [5] Di era sekarang ini agar UMKM dapat terus berjalan dan berlanjut, selain mengikuti kemutakhiran jaman dan mengikuti tren berjualan di masa Pandemi, UMKM perlu juga memiliki izin usaha yang merupakan salah satu wujud izin yang diberikan oleh Pemerintah kepada UMKM sebagai pihak yang menjalankan usaha secara resmi [6].

Memiliki perizinan merupakan sesuatu hal yang menjadi pokok yang wajib bagi pelaku Usaha Mikro, Kecil dan Menengah (UMKM). Pada prinsipnya pengurusan perizinan adalah sama bagi semua usaha, namun yang membedakan adalah jenis usaha atau jenis UMKM yang didirikan. Jenis-jenis UMKM dengan pengertiannya adalah : Usaha Mikro, merupakan usaha produktif yang dimiliki oleh perorangan atau badan usaha termasuk semua kriteria yang diatur dalam Undang-Undang Nomor 20 Tahun 2008, dengan kepemilikan asset 50 juta dan perolehan omset maksimal 300 juta rupiah. Usaha Kecil merupakan usaha produktif perorangan, perorangan ataupun badan usaha dan bukan anak atau cabang perusahaan yang dimiliki, dengan kepemilikan asset 50 juta sampai dengan 300 juta rupiah, dan perolehan omset 300 juta sampai dengan 2,5 milyar rupiah. Sedangkan Usaha Menengah adalah usaha produktif yang diajlankan oleh perorangan maupun badan usaha dan bukan anak atau cabang perusahaan yang dimiliki atau bagian yang langsung atau tidak langsung, dengan kepemilikan asset 500 juta sampai dengan 10 milyar rupiah, dan perolehan omset 2,5 milyar sampai dengan 50 milyar rupiah.[7]

Surat izin yang menyatakan legalitas usaha sangat penting harus dimiliki setiap orang yang mendirikan usaha [8], karena dengan adanya surat izin usaha tersebut menunjukkan bahwa usaha tersebut bukan fiktif dan tidak melanggar hukum [9] Selain daripada itu segala sesuatunya dapat berjalan dengan baik untuk kedepannya dalam memajukannya usahanya, terutama dalam peminjaman modal usaha pengembangan kepada pihak bank. Jenis surat izin yang harus dimiliki bagi UMKM adalah izin SIUP (Surat Izin Usaha Perdagangan), dimana surat izin ini didapatkan berdasarkan kategori modal usaha [10]

Hal-hal tersebut di atas seringkali dialami oleh UMKM sebagai suatu kendala atau masalah klasik [11], tak terkecuali dengan UMKM yang berada di area sekitar Tanjung Duren, tempat dimana Universitas Kristen Krida Wacana (UKRIDA) berada. Sebagai salah satu Perguruan Tinggi dimana ada satu tugas kewajiban dalam Universitas dalam memenuhi tridharma Perguruan Tinggi adalah 
pelaksanaan implementasi pengabdian kepada masyarakat di dalam komunitas masyarakat. Sebagai Universitas yang peduli, merupakan suatu hal yang wajib dilakukan untuk membantu komunitas UMKM yang belum memahami proses perizinan dan pemanfaatan teknologi secara optimal [12]. Untuk meminimalisir kendala ataupun hambatan dalam membantu berkembangnya bisnis UMKM perlu adanya pendampingan dan bimbingan teknis untuk dapat mewujudkan kedua proses tersebut [13] guna membantu meningkatkan omset penjualan UMKM tersebut serta meningkatkan keberlanjutan dari bisnis mereka.

Upaya UKRIDA dalam memberikan mentoring bagi para UMKM sekitar Tanjung Duren, selain merefleksikan wujud implementasi kewajiban Perguruan Tinggi, UKRIDA juga telah turut serta berpartisipasi dalam mendukung program Pemerintah memajukan sektor UMKM agar UMKM tetap terus menjadi penyumbang terbesar bidang sektor perekonomian negara Indonesia.

Tim Abdimas UKRIDA yang terdiri atas 2 (dua) Fakultas yakni Fakultas Teknik dan Ilmu Kompter (FTIK) bekerja sama dengan Fakultas Ekonomi dan Bisnis (FEB) akan melakukan kegiatan pengabdian kepada masyarakat bagi komunitas UMKM yang membutuhkan pelayanan pengabdian kepada masyarakat. Adapun harapan Tim Abdimas untuk kegiatan pelayanan ini dapat bermanfaat dan sangat berfaedah untuk masa depan UMKM itu sendiri.

\section{METODE PELAKSANAAN}

Rancangan kegiatan yang akan dilakukan sebagai wujud pelayanan pengabdian kepada masyarakat adalah sebagai berikut :

\section{A. Tahap Brainstorming dengan Pihak Kelurahan Tanjung Duren}

Untuk lebih mendapatkan analisa situasional dan arahan yang lebih spesifik, kami telah berdiskusi dengan pihak Kelurahan dengan perincian sebagai berikut:

- Mengadakan pertemuan awal pihak Tim Abdimas UKRIDA yakni FTIK dan FEB yang dipelopori oleh Bapak Dr. Lambok (FEB) dengan Bapak Lurah Tanjung Duren (Bapak Iskandar)

- Pihak Kelurahan mengundang Tokoh Masyarakat yang berpengaruh (Bapak Sudradjat) untuk mebantu pelaksanaan teknis di lapangan.

- Merencanakan adanya FGD (Focus Group Discussion) untuk berkoordinasi mematangkan implementasi di lapangan pada hari $\mathrm{H}$.

\section{B. Survei Lokasi}

Fakultas Teknik dan Ilmu Komputer (FTIK) dan Fakultas Ekonomi dan Bisnis (FEB) telah melakukan peninjauan lokasi UMKM sesuai yang diarahkan oleh Bapak Lurah Tanjung Duren., agar Tim Abdimas dapat melakukan pelayanan sesuai perencanaan. Lokasi ini merupakan daerah binaan dari Kelurahan untuk UMKM yang jenis usahanya diantaranya adalah makanan, fotokopi, toko sembako dan kedai minuman.

\section{Pemilihan UMKM}

Lokasi daerah binaan UMKM disekitar Jalan Tanjung Duren Utara seperti yang terlihat pada Gambar 1.

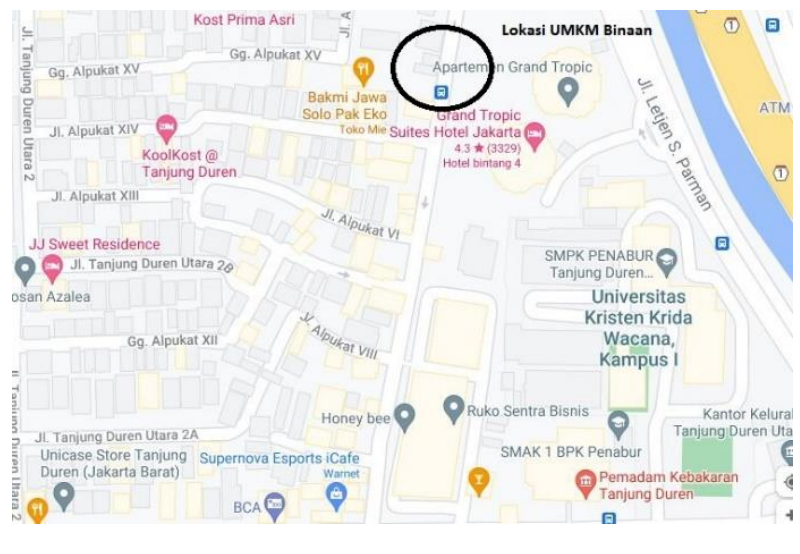

Gambar 1. Lokasi UMKM Binaan

UMKM yang dipilih adalah yang memenuhi kriteria :

- Memiliki karyawan 2-3 orang

- Telah melakukan usahanya sekitar 1 tahun

- Memiliki jenis usaha atau produk yang unik

- Memiliki komitmen dan mau bekerja sama

Pemilihan UMKM ini juga akan melalui persetujuan pihak Kelurahan agar lebih terjaga suasana yang kondusif di lokasi ini. Agar kegiatan ABMAS ini lebih bermanfaat dan memiliki efek bola salju, diharapkan hasil dari kegiatan ini para wakil dari UMKM yang telah dilatih dapat membantu rekan rekannya yang belum terpilih menjadi peserta.

\section{Rencana Pelaksanaan}

Setelah memilih UMKM ,kami akan melakukan peninjauan dan analisa konsep teknologi apa yang tepat untuk diberikan pembimbingan dan penyuluhan. Misalnya pemilihan platform e-commerce yang sesuai dengan skala serta jenis usaha UMKM tersebut. Bila UMKM tersebut belum memiliki iji usaha maka kami akan membantu mereka untuk pengurusan ijin usaha.

E. Tahapan Pendampingan Pengurusan Izin 
Tahapan pendampingan dalam pengurusan izin usaha akan dibimbing oleh salah satu petugas yang ditunjuk oleh pihak Kelurahan yang memahami bidang ekonomi dan perbankan. Tujuan ini agar proses pengurusan izin dapat mudah dilakukan bagi UMKM yang awam belum memahami prosedur secara menyeluruh.

\section{F. Pemberian Edukasi Pemanfaatan Teknologi}

Pemberian edukasi pemanfaatan teknologi akan dilakukan dalam bentuk Seminar secara offline ataupun online yang akan disesuaikan dengan kondisi Pandemi Covid-19. Pemanfaatan teknologi yang rencananya akan diberikan mengarah kepada trend digital seperti bagaimana prospek pemasaran yang baik, bagaimana melakukan pembayaran secara digital, dan bagaimana cara langkahlangkah melakukan pemasaran melalui Instagram, Facebook, dan lain sebagainya.

\section{HASIL PEMBAHASAN}

Pelaksanaan awal sebagai persiapan pelaksanaan kegiatan pengabdian kepada masyarkat yang direncanakan :

\section{A. Pertemuan Untuk Brainstorming Kelurahan dan Tim Abdimas UKRIDA}

Dari pertemuan ini Pak Lurah sangat terbuka dan akan memfasilitas kegiatan ABMAS ini agar terlakasana dengan baik seperti yang ditunjukkan dari Gambar 2 dan Gambar 3. Karena Kelurahan Tanjung Duren memang dinilai sangat berpotensi untuk pengembangan UMKM di sektor makanan dan usaha kecil lainnya yang sangat berkaitan erat dengan kebutuhan para mahasiswa. Hal ini didukung dengan banyaknya tempat kos di sekitar lokasi usaha tersebut yang selalu ramai dari pagi hari sampai malam hari berdasarkan info dari Bapak Sudradjat seperti yang terlihat pada Gambar 4. Dari pihak Kelurahan juga telah menunjuk mediator antara UKRIDA dengan kelompok dari UMKM yang ada di lokasi ini sehingga kegiatan ini dapat menciptakan suasana yang kondusif bagi para usahawan UMKM di sana. Selain itu dukungan tim pengarah juga akan disupport dari Kelurahan sehingga proses penyuluhan akan sangat lengkap dan kepesertaan UMKM yang ikut akan bersifat aktif.

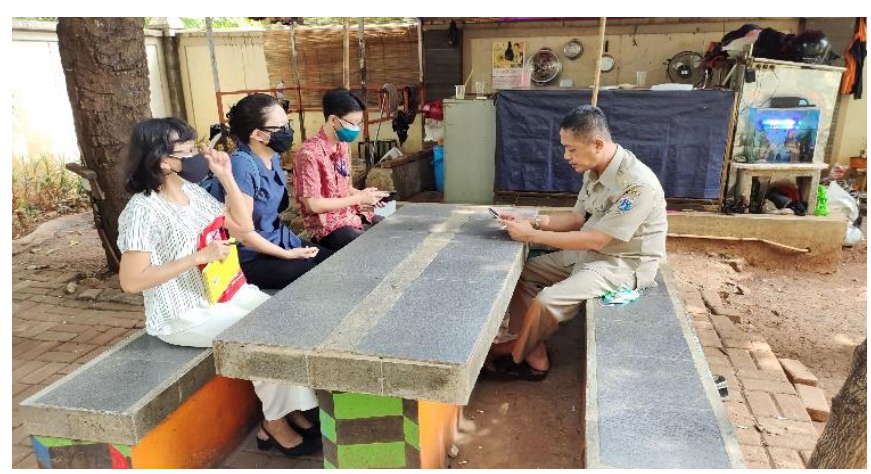

Gambar 2. Tim Abdimas menemui pak Lurah membawa surat permohonan yang dibuat oleh Narahubung Bapak Dr. Lambok Tampubolon

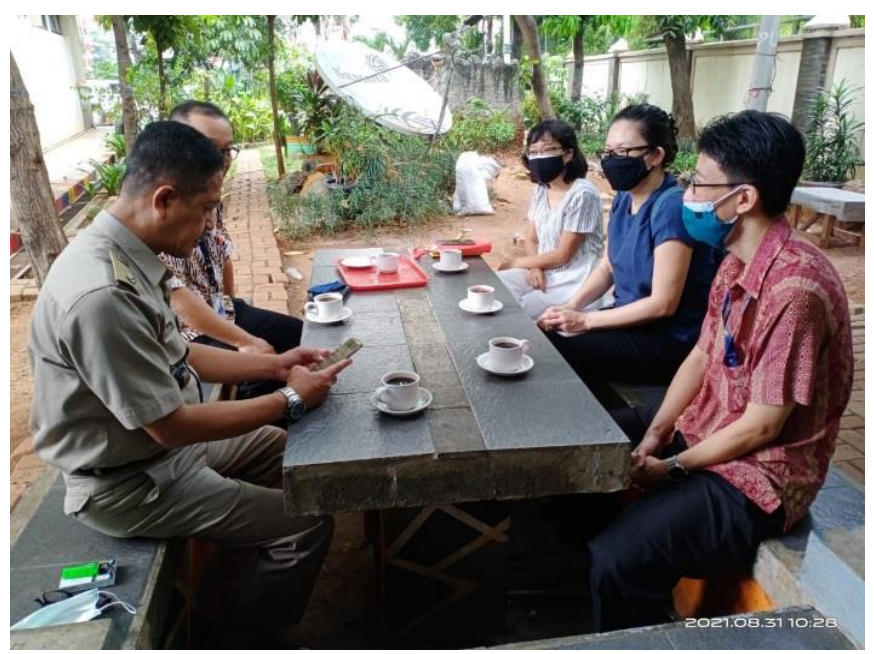

Gambar 3. Pertemuan Tim Abdimas dan pak Lurah Bapak Iskandar

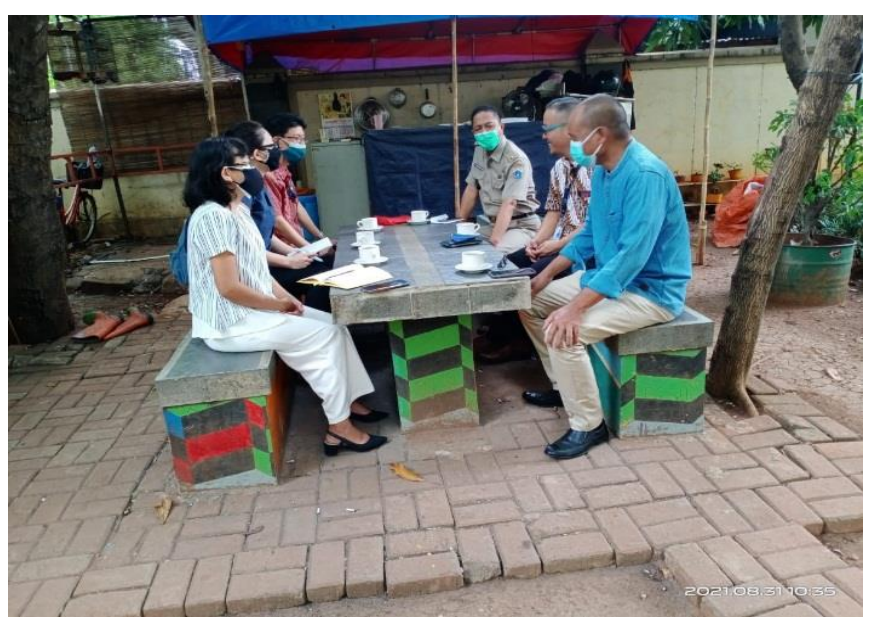

Gambar 4. Tim Abdimas, Bapak Lurah dan Tokoh Masyarakat Bapak Sudradjat 


\section{B. Hasil Survei di lapangan (UMKM) :}
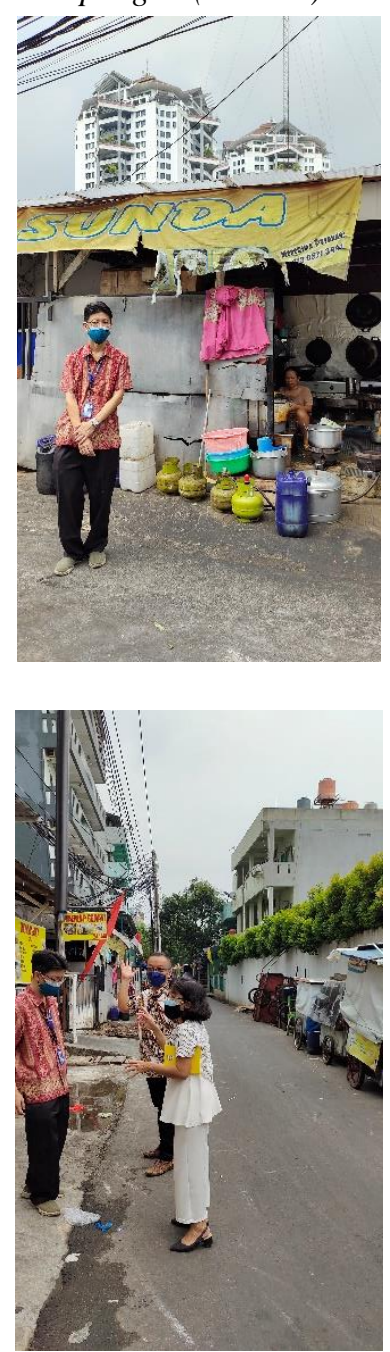

Gambar 5. Survei Lokasi UMKM sesuai arahan Bapak Lurah

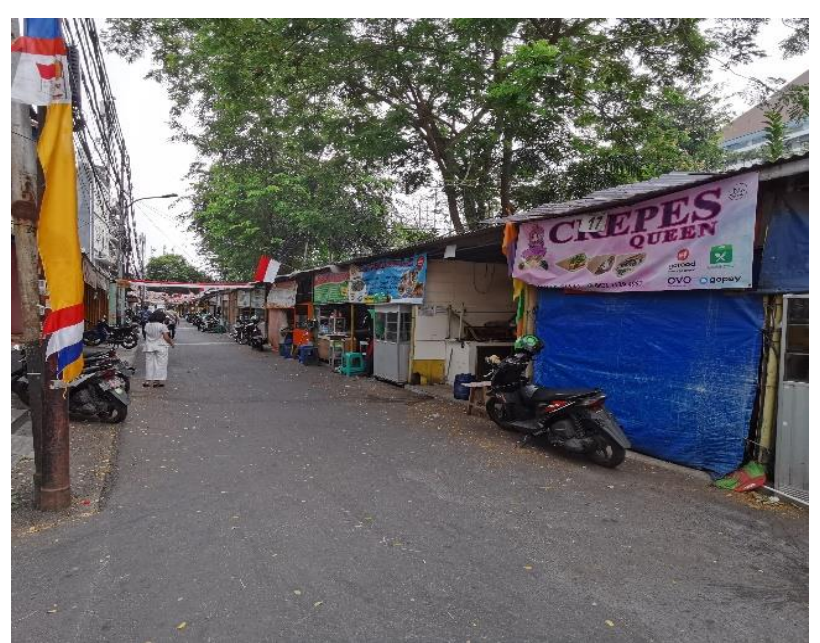

Gambar 6. UMKM yang belum memiliki izin usaha dan pemanfaatan teknologi

Tim abmas juga telah melakukan survei lokasi di sekitar perkumpulan untuk melihat potensi dan situasi lingkungan UMKM seperti yang terlihat pada Gambar 5 dan Gambar 6 .

\section{Rencana Persiapan Tim Abdimas}

- Mempersiapkan contoh poster, flyer dan spanduk untuk pelaksanaan kegiatan pada hari $\mathrm{H}$.

- Mempersiapkan materi penjelasan tahapan pengurusan izin usaha dan pemanfaatan teknologi yang optimal.

- Penunjukan petugas lapangan bidang ekonomi dan aplikasi teknologi yang ditunjuk oleh Bapak Lurah Tanjung Duren yang akan membantu pengurusan izin usaha.

- $\quad$ Agar lebih efektif tim ABMAS dari UKRIDA juga akan mendampingi secara kontinu untuk pelatihan dan proses pengurusan ijin usaha serta proses pendaftaran di platform e-commerce, sehingga para peserta dapat mengerti dan lebih memahami proses proses yang dilakukan dengan lebih detail.

- Untuk pemantauan dan merespon pertanyaaan dari para peserta, dari UKRIDA juga akan menyiapkan tim yang terdiri dari mahasiswa, sehingga mereka dapat lebih sigap merespon bila ada suatu hal yang belum dipahami oleh para peserta pelatihan. Para mahasiswa ini juga akan siap membantu bila ada kesulitan teknik dalam penerapan aplikasi ecommerce yang baru dipelajari oleh para staf UMKM.

Dari kegiatan diatas, sebagai salah satu hasil yang diharapkan adalah dapat meningkatkan pendapat mereka dan dapat menurunkan resiko kegagalan usaha mereka. Selain itu kegiatan ini dapat menjadi contoh yang baik bagi masyarakat sekitar Kelurahan Tanjung Duren, dengan adanya kerja sama yang lengkap dari unsur Akademisi, Pelaku Usaha dan Pemerintah maka akan menghasilkan suatu hal yang sangat berguna dan dibutuhkan bagi masyarakat pelaku kegiatan UMKM ini.

\section{KESIMPULAN}

Sebagai kesimpulan dari rencana kegiatan pelaksanaan pengabdian kepada masyarakat bagi UMKM Tanjung Duren yang ditunjuk oleh Bapak Lurah adalah sebagai berikut:

1. Akan dibantu pengurusan izin usaha bagi 1-2 UMKM yang diarahkan oleh Bapak Lurah melalui pendampingan dari petugas ekonomi dan perbankan yang ditunjuk Bapak Lurah Tanjung Duren dan tim Abmas UKRIDA. 
2. Akan ada pelatihan melalui edukasi e-commerce secara offline atau online pemanfaatan teknologi yang sesuai dari produk UMKM untuk meningkatkan daya jual dan daya tarik konsumen.

3. Akan ada pemantauan dari menfaatkan teknologi yang tepat dengan program yang sesuai untuk mendukung yng dibutuhkan UMKM Tanjung Duren yang ditunjuk Bapak Lurah dan Tim Abmas beserta mahasiswa UKRIDA.

\section{UCAPAN TERIMA KASIH}

Ucapan terima kasih kepada Bapak Iskandar selaku Lurah Tanjung Duren yang telah meluangkan waktunya bertemu dengan Tim Abdimas UKRIDA.

Ucapan terima kasih kepada Tokoh Masyarakat Tanjung Duren Bapak Sudradjat, yang telah menyempatkan diri bertemu dengan Tim Abdimas UKRIDA.

Ucapan terima kasih kepada Rektor UKRIDA (Dr. dr. Wani Devita Gunardi, Sp.MK (K)) yang telah memberikan dukungan penuh bagi Tim Abdimas UKRIDA untuk memulai pelaksanaan kegiatan pelayanan pengabdian kepada masyarakat.

Ucapan terima kasih kepada Dekan FEB UKRIDA (Bapak Dr. Oki Sunardi) dan Dekan FEB UKRIDA (Ibu Dr. Melitina Tecoalu) yang memberikan dukungan optimal sehingga rencana kegiatan awal dapat terlaksana.

Ucapan terima kasih kepada LPPM UKRIDA yang akan memfasilitasi rencana melaksanakan kegiatan pengabidan kepada masyarakat ini.

Ucapan terima kasih kepada pak Yos (UBK3) yang telah membantu pengambilan gambar kegiatan awal, dan Ibu Tati (TU FB) yng membantu administrasi persuratan yang dibutuhkan Tim Abdimas UKRIDA.

\section{DAFTAR PUSTAKA}

[1] S.Hidayat, Pemberdayaan Ekonomi Rakyat. Pustaka Quantum Jakarta 2001.

[2] Alhempi, Raden Rudi dan W Harianto, "Pengaruh Pelatihan dan Pembinaan Terhadap Pengembangan Usaha Kecil pada Program Kemitraan Bina Lingkungan. Media Riset Bisnis dan Manajemen". Vol.13. No.1. pp.20-38. 2013.

[3] T.Pradiani, "Pengaruh Sistem Pemasaran Digital Marketing Terhadap Peningkatan Volume Penjualan Hasil Industri Rumahan. Malang": Jurnal Ilmiah Bisnis dan Ekonomi Asia Vol. 11 No. 2.2018

[4] J. Jauhari, "Upaya Pengembangan Usaha Kecil dan Menengah (UKM) Dengan Memanfaatkan e-Commerce". Jurnal Sistem Informasi, 2(1), $159-168.2010$

[5] Putri, N. M., \& Jember, I. Pengaruh Modal Sendiri dan Lokasi Usaha Terhadap Pendapatan Usaha Mikro Kecil Menengah (UMKM) di Kabupaten Tabanan (Modal Pinjaman Sebagai Variabel Intervening). Jurnal Ekonomi Kuantitatif Terapan, 9(2), 142-150,2016.

[6] T.Ade Irawan, "Evaluasi Regulasi dalam Menciptakan Kemudahan Berusaha bagi UMKM", Jurnal Rechtsvinding, Volume 6 Nomor 3,2017

[7] Firdausy, CM. 2010. Prospek Bisnis UKM dalam Era Perdagangan Bebas dan Otonomi Daerah. Available online with up dates at http:// www.duniaesai.com/ekonomi/eko5.html.

[8] "Kunci Sukses Dalam Bisnis UMKM Di Indonesia Jaman Now," [Online]. Available: https://zonakaya.com/kunci-sukses-dalambisnis-umkm-di-indonesia-di-indonesia-jaman-now/

[[9] "Pentingnya Memiliki Izin Usaha," [Online]. Available: https://ibizcoach.com/pentingnya-memiliki-izin-usaha/.

[10] Cara Menurus Surat Izin untuk UMKM dan Usaha Rumahana [online] available https://idcloudhost.com/cara-mengurussurat-izin-untuk-umkm-dan-usaha-rumahan/

[11] Rajindra, B., Wahba, G., \& Febrianti, D. Pengaruh Modal Kerja dan Kemampuan Produksi Terhadap Kinerja Keuangan UMKM. Jurnal Sinar Manajemen, 5(1), 9-23.2018

[12] Nurpratama, M. Penerapan digital marketing bagi usaha mikro, kecil dan menengah (Umkm) Di Kelurahan Karangmalang Indramayu. Jurnal Investasi, 6(2).2020

[13] Wihartanti, L. V. Faktor-faktor Pendorong Pengusaha UMKM Dalam Mengambil atau Menggunakan Kredit Usaha Rakyat (BRI) di Kabupaten Sragen. Jurnal Promosi, 5(1), 37-46.2017 